\title{
Pore-Scale Imaging of the Oil Cluster Dynamic during Drainage and Imbibition Using In Situ X-Ray Microtomography
}

\author{
Junjian Li, ${ }^{1}$ Yajun Gao $\left(\mathbb{D},{ }^{1,2}\right.$ Hanqiao Jiang, ${ }^{1}$ Yang Liu ${ }^{(D)}{ }^{1}$ and Hu Dong ${ }^{3}$ \\ ${ }^{1}$ State Key Laboratory of Petroleum Resources and Prospecting, China University of Petroleum, Beijing 102249, China \\ ${ }^{2}$ CNOOC Research Institute Co., Ltd., Beijing 100028, China \\ ${ }^{3}$ iRock Technologies Co., Ltd., Beijing 100094, China
}

Correspondence should be addressed to Yajun Gao; gaoyajuncup@163.com

Received 5 September 2017; Revised 22 January 2018; Accepted 18 February 2018; Published 24 April 2018

Academic Editor: Marco Petitta

Copyright (C) 2018 Junjian Li et al. This is an open access article distributed under the Creative Commons Attribution License, which permits unrestricted use, distribution, and reproduction in any medium, provided the original work is properly cited.

\begin{abstract}
We imaged water-wet and oil-wet sandstones under two-phase flow conditions for different flooding states by means of X-ray computed microtomography $(\mu \mathrm{CT})$ with a spatial resolution of $2.1 \mu \mathrm{m} /$ pixel. We systematically study pore-scale trapping of the nonwetting phase as well as size and distribution of its connected clusters and disconnected globules. We found a lower $S_{\text {or }}, 19.8 \%$, for the oil-wet plug than for water-wet plug (25.2\%). Approximate power-law distributions of the water and oil cluster sizes were observed in the pore space. Besides, the $\tau$ value of the wetting phase gradually decreased and the nonwetting phase gradually increased during the core-flood experiment. The remaining oil has been divided into five categories; we explored the pore fluid occupancies and studied size and distribution of the five types of trapped oil clusters during different drainage stage. The result shows that only the relative volume of the clustered oil is reduced, and the other four types of remaining oil all increased. Pore structure, wettability, and its connectivity have a significant effect on the trapped oil distribution. In the water sandstone, the trapped oil tends to occupy the center of the larger pores during the water imbibition process, leading to a stable specific surface area and a gradually decreasing oil capillary pressure. Meanwhile, in oil-wet sandstone, the trapped oil blobs that tend to occupy the pores corner and attach to the walls of the pores have a large specific surface area, and the change of the oil capillary pressure was not obvious. These results have revealed the well-known complexity of multiphase flow in rocks and preliminarily show the pore-level displacement physics of the process.
\end{abstract}

\section{Introduction}

Dynamic characteristics of multiphase flow in porous media are closely related to the oil and gas industry. Accurate description of the trapped phase distribution in an underground formation has always been a difficult task in oilfield developments. Furthermore, advanced understanding of pore structure geometries and fluid dynamic distribution during drainage is the foundation of enhancing oil recovery.

A significant amount of work has been completed to study two-phase flow at macroscopic scales $[1,2]$. On the other hand, a large number of testing models, such as twodimensional micromodels $[3,4]$ and network models [57], have been proposed. It is a huge challenge to accurately characterize three-dimensional, residual phase features in real rocks. However, the macroscopic oil-water seepage characteristics are the larger-scale response of fluid flow behaviors at the pore scale. There is therefore significant interest in determining the change of the morphological characteristics and size distribution of residual clusters, which is important for numerical simulations and experimental and imaging techniques.

During the past ten years, the CT scanning technique has been widely used to study pore structure and fluid distribution [8-10]. Multiphase fluid saturations were measured in situ at the pore scale to explain deviations of saturation exponent from conventional values [11]. Wettability was then regarded as a critical factor which could influence droplet quantity [12], sweep efficiency [13], residual saturation [14], and size distribution of trapped clusters $[15,16]$. Moreover, the remaining oil saturation in a water-wet system is about a 
TABLE 1: Main petrophysical properties of the sandstone plugs.

\begin{tabular}{lccccc}
\hline Plug & WI & Helium porosity $(\%)$ & Permeability $(\mathrm{mD})$ & Diameter $(\mathrm{mm})$ & Length $(\mathrm{mm})$ \\
\hline Water-wet & 0.74 & 13.7 & 188.3 & 7.64 & 50 \\
Oil-wet & -0.64 & 22.9 & 622.5 & 7.68 & 50 \\
\hline
\end{tabular}

factor of two larger than that obtained in the mixed-wet rock [17].

A lot of experiments have been conducted to study the size distribution of trapped clusters (ganglia) after drainage, since it was considered the most important property of the pore network within a rock besides saturation. $\mathrm{CO}_{2}$ geostorage capacities and oil recovery efficiency have been investigated by many researchers. It has been widely reported that the size distribution of residual clusters obeys a powerlaw distribution with an exponent, $\tau$ [16, 18-25]. Previous results showed that the power-law exponent, $\tau$, for oil-wet cores is higher than water-wet cores, which indicates fewer large clusters in oil-wet cores (Iglauer et al., 2015 [16, 26]). In addition, rock chemical properties have little influence on the size of residual gas clusters [23]. The characteristic cluster size and saturation distributions have been discussed in detail in different stages of drainage and imbibition processes, and the value of $\tau$ almost did not change during the entire process [24]. Also, the surface area of each cluster against its volume and curvature distribution were measured (Iglauer et al., $2015[19,27])$, which fully demonstrated the well-known complexity of multiphase transport in rocks.

In this study, we obtained wetting and nonwetting phase cluster geometries in sandstones with microcomputedtomography imaging and investigated the developments of clusters size distribution, cluster morphologies, surface areas, and capillary pressure distributions during drainage processes.

\section{Material and Methods}

2.1. Experimental Procedure. The flow experiments were conducted on two different plugs, which were drilled from larger plugs. The plugs were well sorted and relatively homogeneous, which were from the Carboniferous marine detrital fine sandstone within the Xinjiang oilfield located in the Tarim Basin. The wettability was determined by spontaneous imbibition experiments under room temperature and pressure. To acquire more accurate data, the independent experiments were conducted on the same separate larger plugs (diameter $=25.4 \mathrm{~mm}$, length $=80 \mathrm{~mm}$ ) and the wettability indexes (WI) were calculated by Amott's method [28]. Detailed petrophysical and wettability properties of the plugs are illustrated in Table 1 . The porosity and permeability were obtained from the small plugs, which were used in the CT imaging experiments. The porosity was obtained by helium porosity automatic tester and the permeability was obtained by the flow experiment in laboratory. The plugs were placed in a carbon fiber core holder and high temperature and pressure can be applied on it during the experiment. Mineral oil and brine were used in the displacement experiment, and the oil-brine interfacial tension was $0.062 \mathrm{~N} / \mathrm{m}$. $10 \mathrm{wt} \%$ sodium iodide (NaI) was added in the distilled water to enhance the effective contrast between the oil and brine; this allowed for realistic reservoir salinities to be preserved. The viscosity and density of the oil are $4.58 \mathrm{mPa} \cdot \mathrm{s}$ and $818 \mathrm{~kg} / \mathrm{m}^{3}$, respectively, at room temperature and pressure.

The same experiment was performed on both plugs. Each experiment consisted of the following steps:

(1) The plug was placed in the plug holder under reservoir condition, temperature $\left(55^{\circ} \mathrm{C}\right)$ and pressure $(12 \mathrm{MPa})$, and then the first scanning was performed to obtain a reference dry scan. The confining pressure of $15 \mathrm{MPa}$ was applied during all experiment.

(2) The plug was vacuumed and then fully saturated with brine. The plug was flushed by about more than 120 pore volumes (PVs) of brine in order to reach a chemical equilibrium between rock minerals and brine. The injection flow rate was $0.01 \mathrm{~mL} / \mathrm{min}$ at first and then gradually increased after 100$\mathrm{PV}$ brine injection but was always lower than $0.05 \mathrm{ml} / \mathrm{min}$, and then the plug was scanned secondly with X-ray CT.

(3) $1 \mathrm{PV}$ of oil was flushed through the plug at an injection rate of $0.01 \mathrm{ml} / \mathrm{min}$, which corresponds to a low capillary number with $N_{\text {cap }}=v \mu / \sigma=1.1 \times 10^{-7}$. In the next step, $100 \mathrm{PVs}$ of oil were injected at the same flow rate to establish irreducible water condition. The third and fourth CT scanning were performed at the end of the two saturation states, respectively.

(4) $1 \mathrm{PV}$ of brine displacement at the same flow rate was conducted. And then $100 \mathrm{PVs}$ of brine were injected to establish residual oil state. The fifth and sixth CT scans of the sandstone were conducted, respectively.

The injection rate schedule is displayed in Figure 1. Prior to each CT scanning, the pump was turned off. In situ CT scanning was performed through the experiment. The $\mathrm{X}$ ray source was aligned with the geometrical center of the plug, which was $25 \mathrm{~mm}$ above the bottom of the plug. We performed the CT scanning at a resolution of $2.1 \mu \mathrm{m} /$ pixel and one CT scan took approximately 30 minutes. The entire scanning field of view was approximately $3.5 \mathrm{~mm} \times 3.5 \mathrm{~mm}$ $\times 2 \mathrm{~mm}$; the 3D data which we obtained are located at the middle of the plug and far from the end of it, so it can be very good to avoid the end capillary pressure effects.

2.2. Image Processing. The plug was perpendicular to the horizontal plane in the micro-CT scanner, the inlet was on the bottom of the plugs, and the outlet was on the top of the plugs (Figure 1). The slices were horizontal cross-sectional images of the plug. After 3D reconstruction, the images were filtered with a nonlocal means to preserve edges [29]. Figure 2(a) was obtained from the scanning of dry plug. Actually, the segmentation process was followed by extracting the pore space and the solid from the dry reference image using the histogram-thresholding method, which can very clearly 


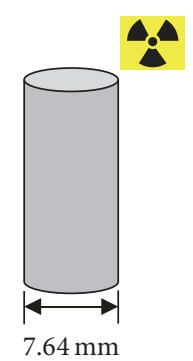

Dry Sample

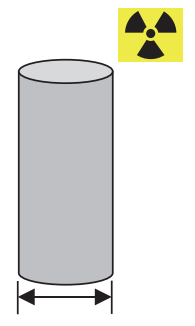

$7.68 \mathrm{~mm}$

Dry Sample

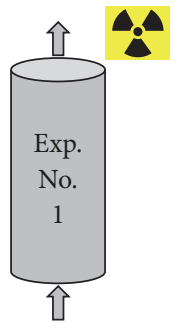

Vacuum saturation

$Q_{\mathrm{w}}<0.05 \mathrm{~mL} / \mathrm{min}$

$\mathrm{PV}_{\mathrm{w}}>100 \mathrm{PV}$

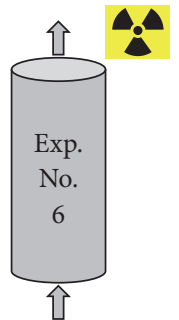

Vacuum saturation

$Q_{\mathrm{w}}<0.05 \mathrm{~mL} / \mathrm{min}$

$\mathrm{PV}_{\mathrm{w}}>100 \mathrm{PV}$

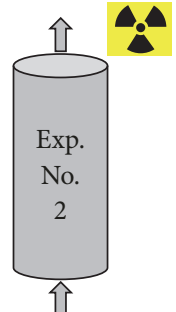

First drainage

$Q_{\mathrm{o}}=0.01 \mathrm{~mL} / \mathrm{min}$

$\mathrm{PV}_{\mathrm{o}}=1 \mathrm{PV}$

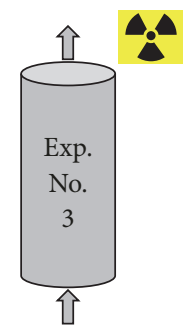

Second drainage

$Q_{0}=0.01 \mathrm{~mL} / \mathrm{min}$

$\mathrm{PV}_{\mathrm{o}}=100 \mathrm{PV}$

(a)

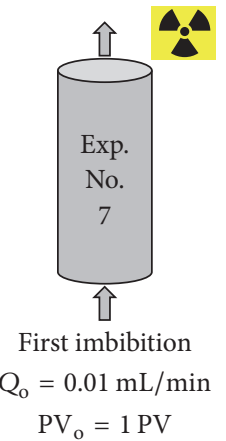

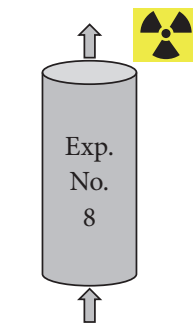

Second imbibition

$Q_{\mathrm{o}}=0.01 \mathrm{~mL} / \mathrm{min}$

$\mathrm{PV}_{\mathrm{o}}=100 \mathrm{PV}$

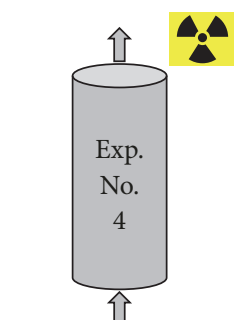

First imbibition

$Q_{\mathrm{W}}=0.01 \mathrm{~mL} / \mathrm{min}$

$\mathrm{PV}_{\mathrm{w}}=1 \mathrm{PV}$

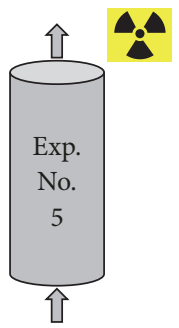

Second imbibition

$Q_{\mathrm{W}}=0.01 \mathrm{~mL} / \mathrm{min}$

$\mathrm{PV}_{\mathrm{w}}=100 \mathrm{PV}$

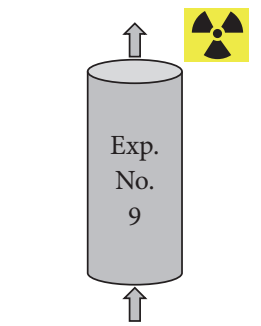

First drainage

$Q_{W}=0.01 \mathrm{~mL} / \mathrm{min}$

$\mathrm{PV}_{\mathrm{w}}=1 \mathrm{PV}$

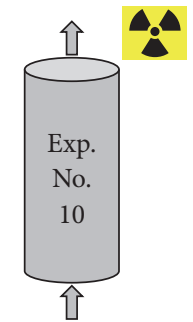

Second drainage

$Q_{\mathrm{W}}=0.01 \mathrm{~mL} / \mathrm{min}$

$\mathrm{PV}_{\mathrm{w}}=100 \mathrm{PV}$

(b)

FIGURE 1: Schematic illustration of all experimental stages performed on (a) water-wet and (b) oil-wet plugs $\left(Q_{\mathrm{w}}\right.$ and $Q_{\mathrm{o}}$ are the injection rate of brine and oil, resp.; $\mathrm{PV}_{\mathrm{w}}$ and $\mathrm{PV}_{\mathrm{o}}$ are the quantity of injection pore volume of brine and oil, resp.).

distinguish each phase; see Figure 2(b). In Figure 2(c), which was obtained from Exp. number 4 (Figure 1), the gray value of $\mathrm{NaI}$ solution was the greatest, the gray value of oil was the lowest, and the gray value of rock was in the middle. After registering and aligning each set of the wet images with its corresponding dry reference image, the solid can be accurately separated from the wet image (Figure 2(c)) and then the combined image contained only fluid phases with enough phase contrasts to be distinguished, Figure 2(e). Finally, we can obtain the segmented wet image and threedimensional rendering of the oil and water phases, as shown in Figures 2(e) and 2(f). The segmented images were then analyzed in order to obtain the saturation of each phase, clusters volumes and surface areas, clusters surface curvature, and essential rock properties including pore size distribution and its connectivity. All image processing was conducted by using Image J and Avizo Fire 8.0.

\section{Results and Discussion}

3.1. Representative Elementary Volume (REV). To analyze the characteristic of residual oil in the experiment, we calculated both porosity- and saturation-based REVs for each sample using two drainage and two imbibition data sets. We generated several cubical subvolumes with various side lengths ranging from 0.105 to $2.73 \mathrm{~mm}$ and then calculated porosity and oil saturation for each one. It has been investigated that the field of view (FOV) in paper was larger than the representative elementary volume (REV) of plugs; see Figure 3.
And hence the porosity and saturation values calculated over FOVs can be considered representative of the overall values in the samples.

3.2. Pore Throat Characteristics. Figure 4 shows the pore size distribution for both water-wet plug and oil-wet plug. It was observed that the pore radius for water-wet plug was located almost at the vicinity of $10 \mu \mathrm{m}$, and the distribution range was significantly smaller than oil-wet plug. Figure 5 shows the pore connectivity of both plugs. We use the connectivity function defined by Vogel and Roth to calculate the pore connectivity [30]. The connectivity function was expressed as

$$
\chi_{V}(r)=\frac{N_{N}(r)-N_{B}(r)}{V},
$$

where $N_{N}(r)$ is the number of pores with radius larger than $r, N_{B}(r)$ is the throat number with radius larger than $r$, and $V$ is the pore volume.

The pore connectivity of oil-wet plug was better since the well-connected pore size distribution range of water-wet plug was narrower $(5 \mu \mathrm{m}-20 \mu \mathrm{m})$ than that of oil-wet plug $(25 \mu \mathrm{m}-70 \mu \mathrm{m})$.

3.3. Cluster Size Distributions. We measured the oil and water saturations on the basis of the CT images, Table 2. The irreducible water saturation $\left(S_{\mathrm{wi}}\right)$ in the oil-wet plug $(21.5 \%)$ was lower than the $S_{\mathrm{wi}}$ value in an analogous water-wet system $(31.4 \%)$, and the residual oil saturation $\left(S_{\text {or }}\right)$ in the oilwet plug $(19.8 \%)$ was lower than the $S_{\text {or }}$ value in an analogous 


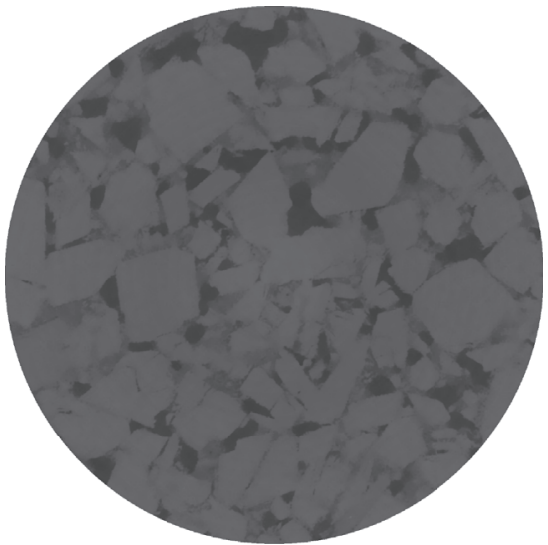

(a)

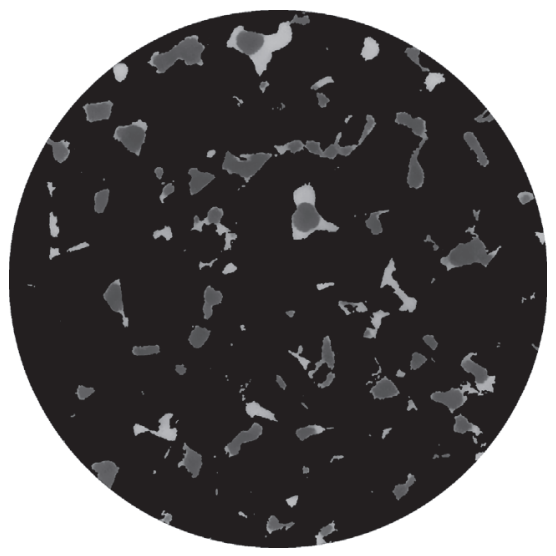

(d)

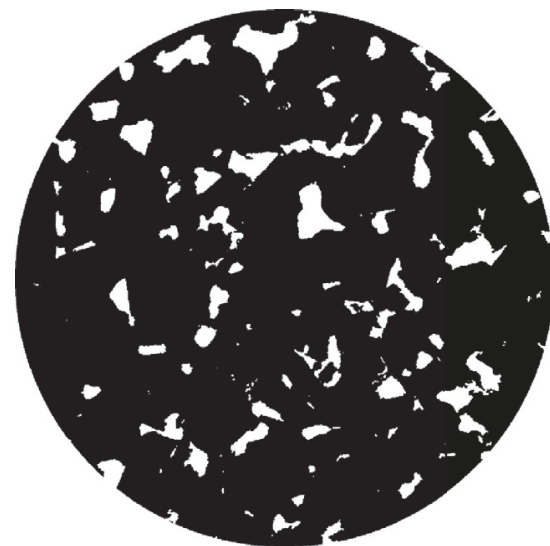

(b)

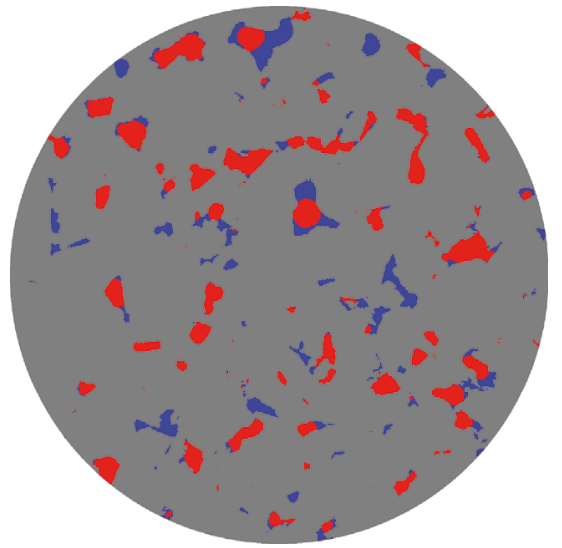

(e)

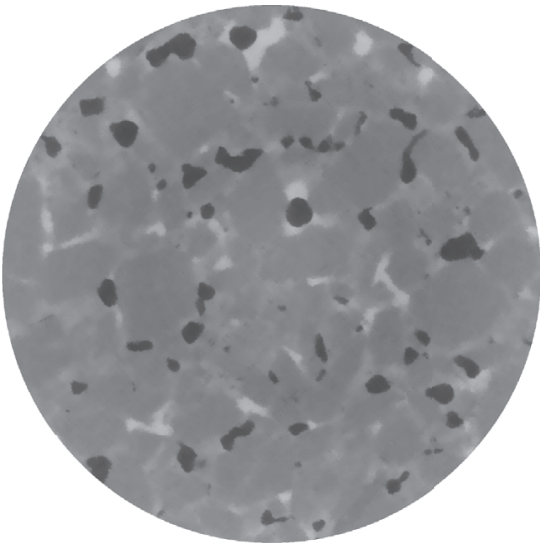

(c)

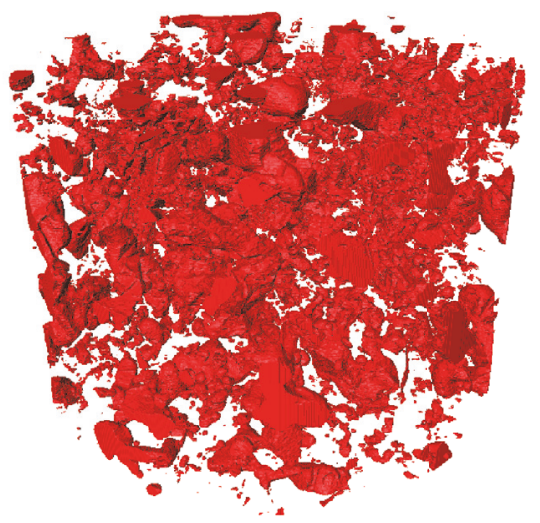

(f)

Figure 2: Horizontal cross-sectional slices through the plug (diameter $=1400$ voxel) and the image processing workflow of wet and dry images taken during the water-wet plug flooding (slice number $=135,24.92 \mathrm{~mm}$ from the inlet). (a) Filtered dry reference image; (b) pore map obtained from the filtered dry image, where the pore is transparent and the grain is black; (c) filtered wet image, where the darkest phase is oil, the light gray phase is brine, and the intermediate phase is solid particle; (d) combined wet image, where oil, brine, and the solid are dark gray, light gray, and black, respectively; (e) segmented wet image (brine: blue; oil: red; and grains: gray); (f) three-dimensional rendering of the oil phase. Brine and rock are transparent for effective visualization.

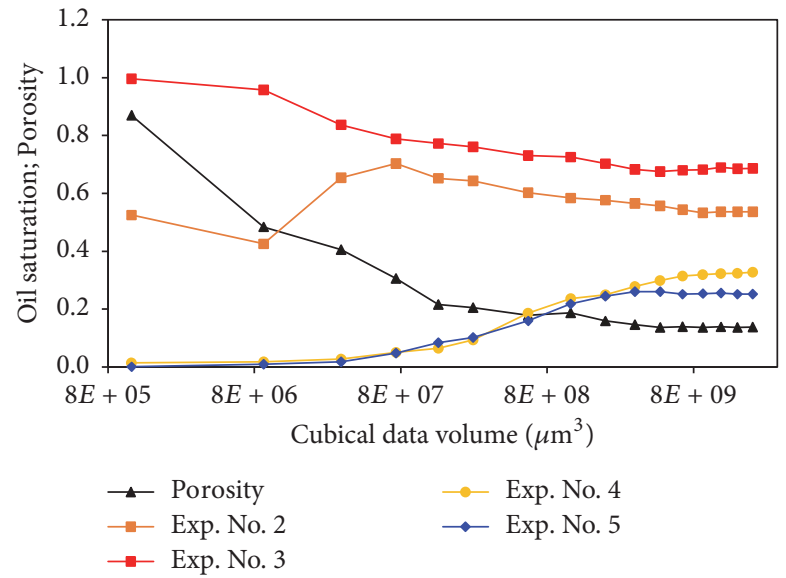

(a)

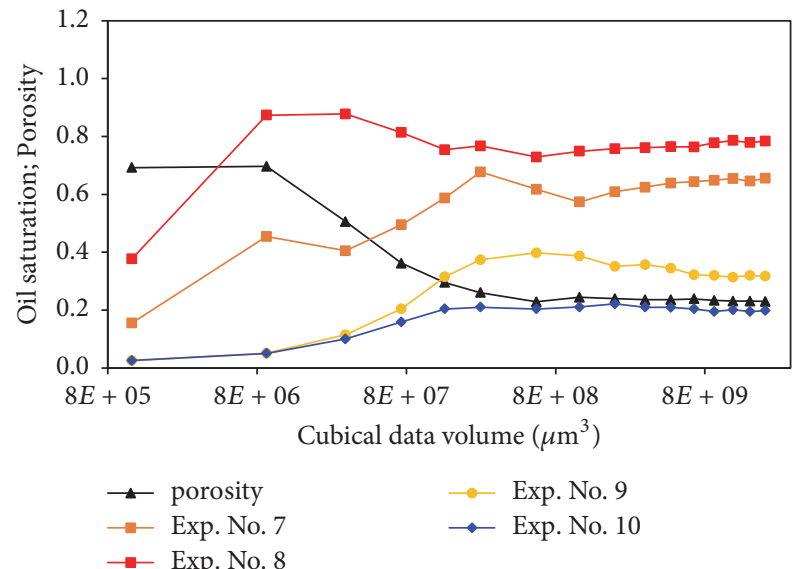

(b)

FIGURE 3: Variation of porosity and oil saturation with various subsample volumes for (a) water-wet and (b) oil-wet plug samples. 
TABLE 2: Statistical parameters associated with the fluid clusters for the two plugs.

\begin{tabular}{|c|c|c|c|c|c|c|c|}
\hline Plug & Experimental process & $S_{\mathrm{w}}$ & $S_{\mathrm{o}}$ & $\tau$, water & $\tau$, oil & $p$, water & $p$, oil \\
\hline \multirow{5}{*}{ Water-wet } & Vacuum saturation (Exp. number 1) & $97.3 \%$ & - & 1.52 & - & 0.77 & - \\
\hline & First drainage (Exp. number 2) & $46.4 \%$ & $53.6 \%$ & 1.34 & - & 0.75 & - \\
\hline & Second drainage (Exp. number 3 ) & $31.4 \%$ & $68.6 \%$ & 0.95 & 0.67 & 0.72 & 0.76 \\
\hline & First imbibition (Exp. number 4) & $67.3 \%$ & $32.7 \%$ & - & 0.98 & - & 0.76 \\
\hline & Second imbibition (Exp. number 5) & $74.8 \%$ & $25.2 \%$ & - & 1.06 & - & 0.75 \\
\hline \multirow{5}{*}{ Oil-wet } & Vacuum saturation (Exp. number 6) & $95.4 \%$ & - & 0.74 & - & 0.74 & - \\
\hline & First imbibition (Exp. number 7) & $34.4 \%$ & $65.6 \%$ & 0.85 & - & 0.73 & - \\
\hline & Second imbibition (Exp. number 8) & $21.5 \%$ & $78.5 \%$ & 0.90 & 1.54 & 0.72 & 0.78 \\
\hline & First drainage (Exp. number 9) & $68.3 \%$ & $31.7 \%$ & - & 1.39 & - & 0.77 \\
\hline & Second drainage (Exp. number 10) & $80.1 \%$ & $19.8 \%$ & - & 1.12 & - & 0.72 \\
\hline
\end{tabular}
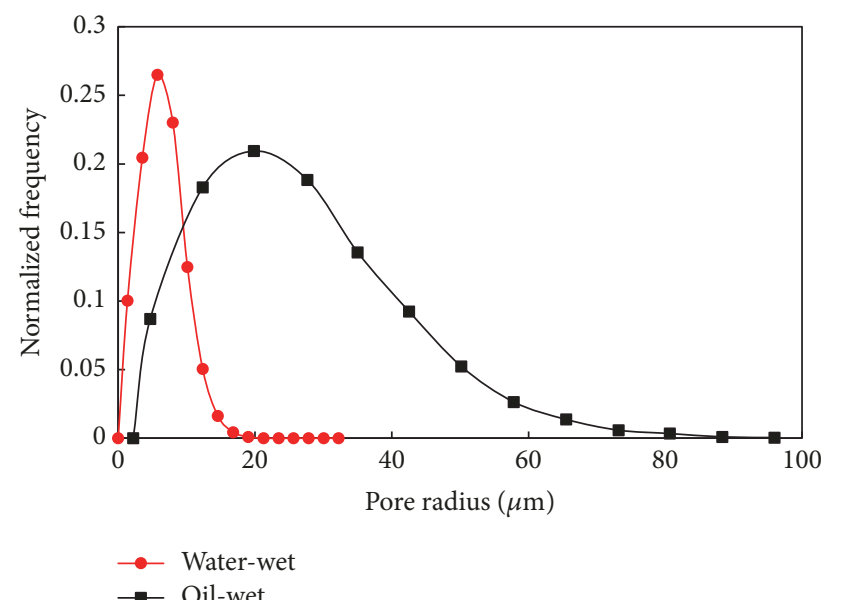

FIgURe 4: Pore size distribution.

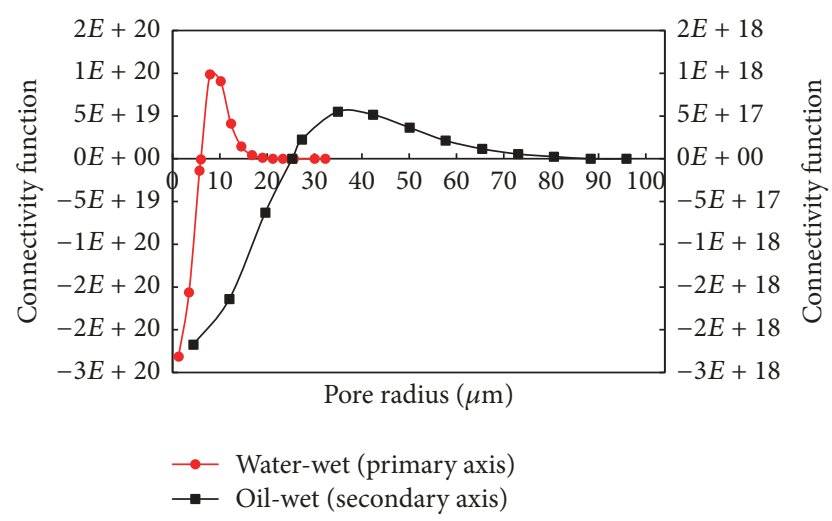

Figure 5: Pore connectivity distribution.

water-wet system $(25.2 \%)$. The $S_{\text {or }}$ relative values for the two plugs are consistent with the findings from other studies $[16,31]$. As we all know, capillary pressure is favorable for oil recovery in water-wet system. But, comparing these two cores, in addition to the effects of wettability, the permeability, average pore radius, and pore connectivity of the oil-wet sandstone were all much greater than those of the water-wet sandstone. Thus, the $S_{\text {or }}$ value for the oil-wet sandstone was lower. So we can see that the oil recovery cannot only be affected by wettability; the pore structure and property also play an important role in oil transport. We also observed that the number of clusters in the oil-wet plug was larger than in the water-wet plug. What is more, we can find that almost $80 \%$ of the volume of oil in the plugs was produced after 1PV water flooding, and the oil recovery of subsequent water flooding was very low; see Table 2 .

With the continuous injection of oil and water, not only did the saturations change, but also the clusters of two-phase fluids in the pores were redistributed constantly. It has been reported that the size of the trapped clusters follows the power-law correlation in accordance with percolation theory $[32,33]$, which is given by $N(s) \sim s^{-\tau}$, where $N(s)$ is the number frequencies of cluster size, $s$. The exponent, $\tau=$ 2.189, was reported in a previous study [34]. Researchers have obtained a wide range of $\tau$ values using different methods, ranging between 1.8 and 2.3 [18, 22-24, 35]. Two summation methods have been proposed by Dias and Wilkinson; however, they lack sufficient theoretical basis to approve $\tau$ value to be larger than 2 [21]. Due to the scan resolution and random noise, the smaller clusters quantity we acquired may be inaccurate, so the $\tau$ value was estimated without considering the smaller clusters. Hence, we derived the $\tau$ value through the normalized frequencies by cutting off the smaller oil/water clusters (smaller than 10 voxels ${ }^{3}$ ). The size distributions of water and oil clusters are shown in Figure 6. The $\tau$ values of the displaced phase in different experimental stage are shown in Table 2.

In the displacement process, the $\tau$ value of the wetting phase gradually decreased and that of the nonwetting phase gradually increased for both plugs, as presented in Table 2 and Figure 7. The number of small oil clusters increased more significantly in the water-wet plug, which resulted in a relative higher frequency; thus, the $\tau$ value grew gradually. For the oil-wet plug, the frequency of intermediate-size oil clusters increased while that of smaller clusters was relatively low, both of which cause the reduction of $\tau$ value. Moreover, due to the better pore structure and oil-wet features, there are several larger clusters in oil-wet plug, as shown in red dotted circle in Figure 6(b).

Figure 8 shows the cross-sectional views of the pore-scale fluid occupancy and distribution in water-wet and oil-wet 

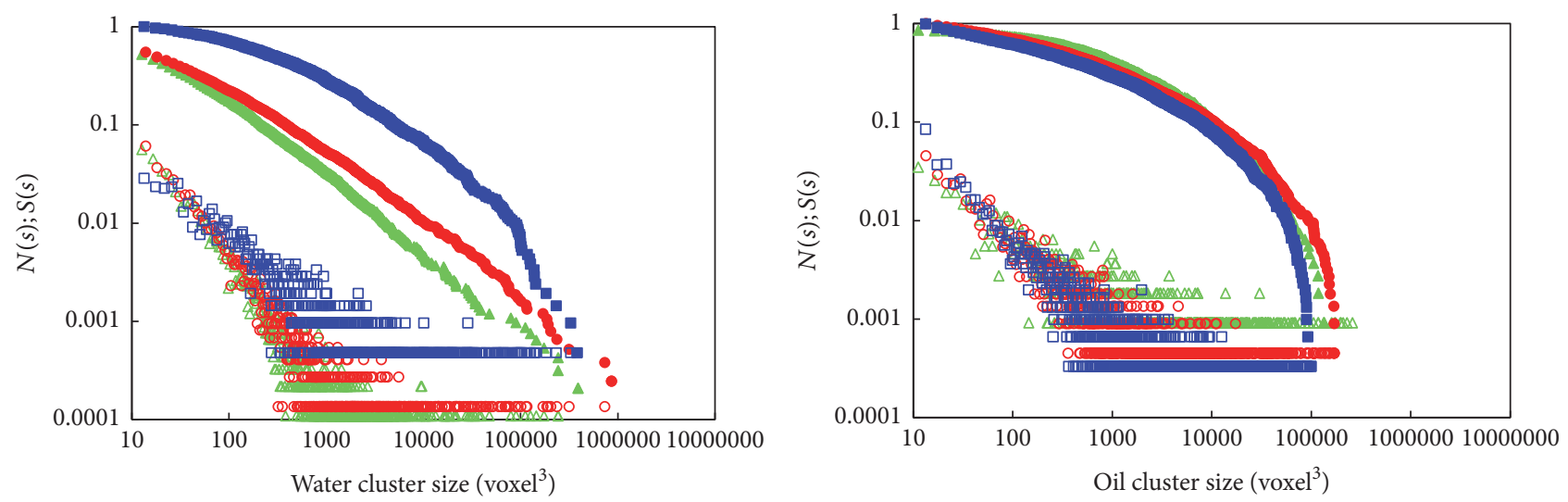
$\triangle$ Exp. No. 1-Ns
$\triangle$ Exp. No. 1 -Cs
- Exp. No. 2-Ns
- Exp. No. 2-Cs
口 Exp. No. 3-Ns
- Exp. No. 3-Cs

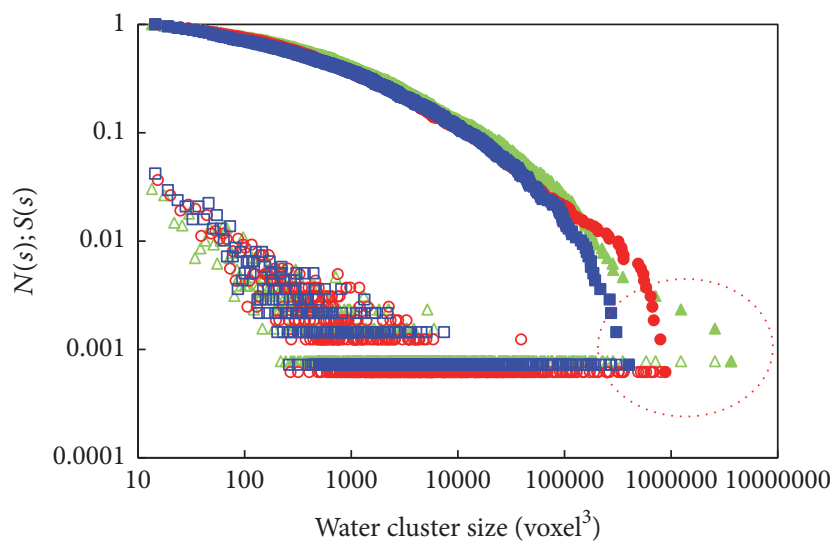
$\triangle$ Exp. No. 6-Ns
- Exp. No. 7-Cs
$\triangle$ Exp. No. 6-Cs
口 Exp. No. 8-Ns
- Exp. No. 8-Cs

(a)
$\triangle$ Exp. No. 3-Ns
- Exp. No. 4-Cs
$\triangle$ Exp. No. 3-Cs
口 Exp. No. 5 -Ns
- Exp. No. 4-Ns
- Exp. No. 5 -Cs

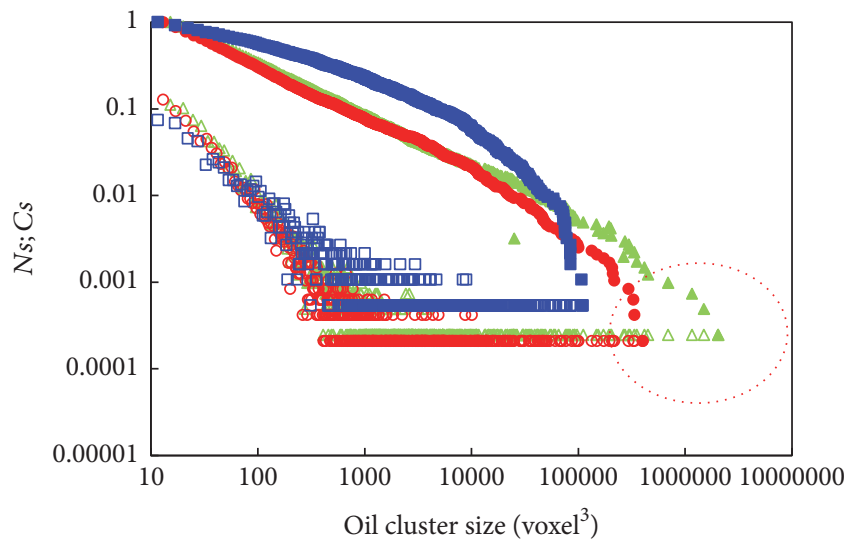

(b)

Figure 6: Water and oil cluster size distributions for the displacement process: (a) water-wet plug and (b) oil-wet plug. $N(s)$ is the normalized distribution and $S(s)$ is the cumulative normalized distribution.

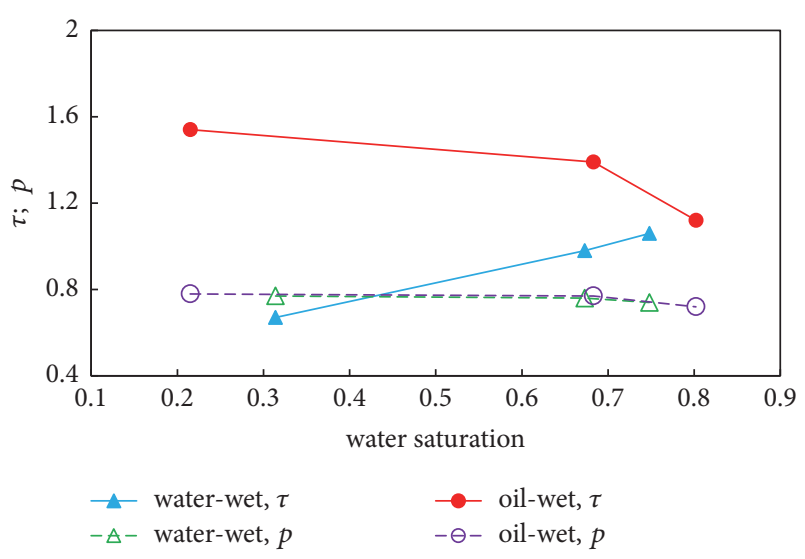

FIGURE 7: Exponent change of the power-law distributions of oil clusters during the water injection. plugs at the end of three displacement stages. The figure illustrates that the oil-wet plug was saturated more fully than water-wet plug after 100-PV oil flush (Figures 8(a) and $8(\mathrm{~d}))$. In the water-wet plug, the remaining oil tends to occupy the larger pore corner after 1-PV water imbibition (Figure $8(\mathrm{~b})$ ), and then some remaining oil in the pore corner gradually moves to the center of pores during subsequent water imbibition (Figure 8(c), black square). The clusters are larger and more roundish than those in oil-wet plug. Due to the water imbibition, the oil is squeezed from the corner into the center of the pores. Some of the initial oil-free pores at the end of $1 \mathrm{PV}$ will be reoccupied by oil during the subsequent water injection process; see yellow square in Figure $8(\mathrm{c})$. Due to the better continuity of the oil phase before water injection in the water-wet plug, the oil in some of the larger pores was almost displaced fully during the primary water flooding. During the remainder of the water injection 


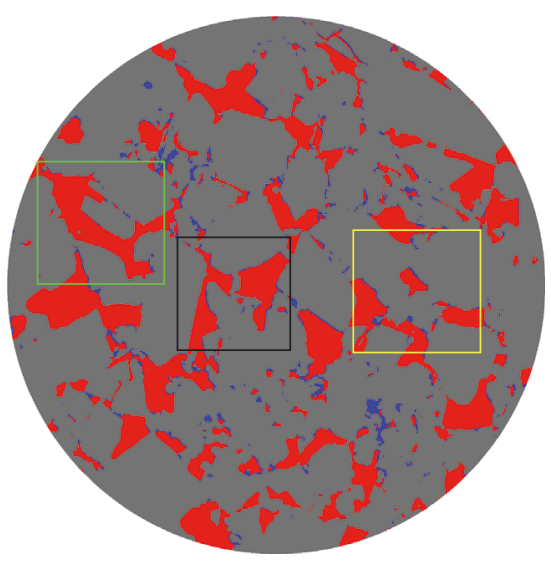

(a)

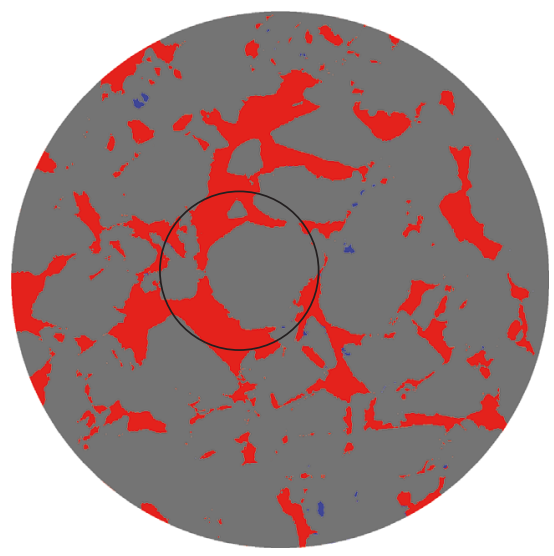

(d)

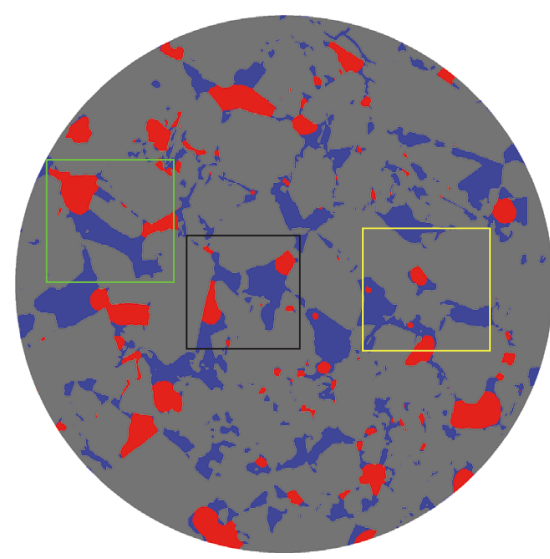

(b)

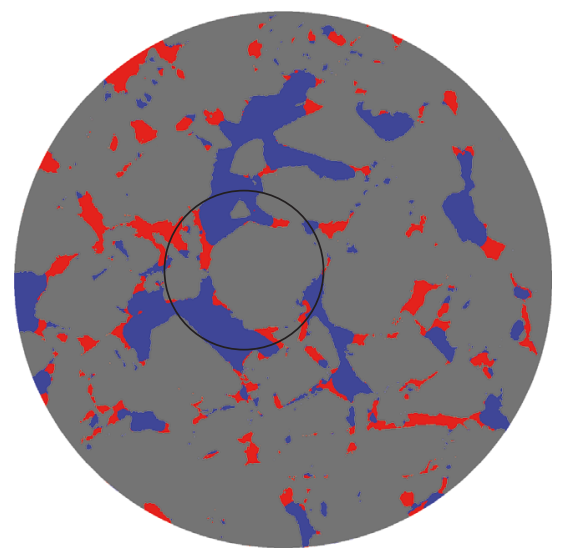

(e)

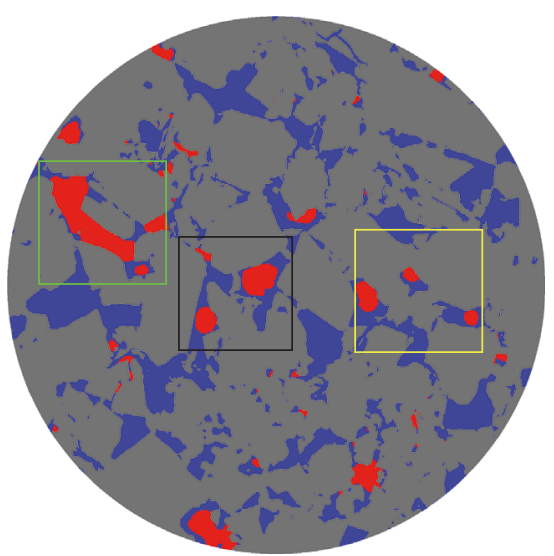

(c)

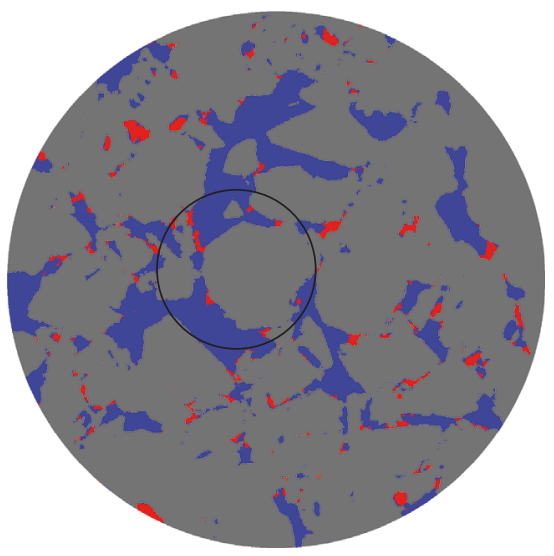

(f)

FIGURE 8: Two-dimensional cross-sectional views (diameter $=1600$ voxels) of the pore-scale fluid occupancy in both water-wet $($ slice $=834$, $25.75 \mathrm{~mm}$ from the inlet) and oil-wet plugs (slice $=158,24.33 \mathrm{~mm}$ from the inlet). (a) Exp. number 3 in water-wet plug. (b) Exp. number 4 in water-wet plug. (c) Exp. number 3 in water-wet plug. (d) Exp. number 8 in oil-wet plug. (e) Exp. number 9 in oil-wet plug. (f) Exp. number 10 in oil-wet plug.

processes, the discontinuous phase oil in the small pores was gradually being removed with the help of favorable capillary pressure. When the discontinuous phase oil was carried to the large pores, they tend to change into almost spherical shape due to the interfacial tension without pore wall constraints. Then the flow resistance would increase at the pore throat transition place, whereas the water with less flow resistance would bypass the oil blob, which caused the oil blob to be trapped in the pore center. So the oil-free void pores may be reoccupied by oil in the end. There are also some much larger pores which are almost fully reoccupied by oil phase at the end of the water flooding (Figure $8(\mathrm{c})$, green square). As mentioned above, the discontinuous phase oil in small pores with higher capillary pressure which can be easily moved and some oil blobs which are smaller than the diameter of the pore throat also can be easily carried by water in the pore net. When they met and got accumulated at the larger pore this resulted in a large oil blob being formed (discontinuous), so the drag force in those pores needs to increase to keep the oil moving. As a result, the water phase would prefer to flow through the pore with less resistance (some oil-free pores).
As shown in Figure 8(e), the remaining oil tends to occupy the pore corner, connected through the thin oil layer in oil-wet plug, which led to more intermediate-size oil clusters and lower $\tau$ value. The oil phase in the oilwet plug tends to maintain a continuous phase, which contributes to be a high effective permeability of oil phase and a higher oil recovery. After drainage by plenty of water, the remaining oil mainly either occupies the corner of the pores or becomes in the form of thin oil layer attached to the pore wall (Figure $8(\mathrm{f})$ ). The change in $\tau$ value also shows that the trapped oil in the water-wet plug is much more difficult to produce than in the oil-wet plug just by water flooding. The $\tau$ values of the trapped $\mathrm{CO}_{2}$ clusters were also found to be higher than the initial state [26]. In addition, the relatively low resolution might explain why the change of $\tau$ value during the displacement process was not noticeable in pervious study. With data fitting, we obtained $\tau=1.12$ in the oil-wet sandstone, which was higher than that of the water-wet sandstone $(\tau=1.06)$, which was consistent with the findings from other groups [12, 16]. 
TABLE 3: Dynamic changes of each type of remaining oil during the water injection.

\begin{tabular}{|c|c|c|c|c|c|c|c|c|}
\hline \multirow{2}{*}{ Plug } & \multirow{2}{*}{ Experimental process } & \multicolumn{5}{|c|}{ Contribution to overall remaining oil volume } & \multicolumn{2}{|c|}{ Largest individual oil cluster } \\
\hline & & Clustered & Multiporous & Columnar & Droplet & Membranous & Volume $\left(10^{6} \mu \mathrm{m}^{3}\right)$ & Area $\left(10^{5} \mu \mathrm{m}^{2}\right)$ \\
\hline \multirow{3}{*}{ Water-wet } & Exp. number 3 & $87.15 \%$ & $8.41 \%$ & $2.32 \%$ & $1.43 \%$ & $0.69 \%$ & 2.41 & 4.49 \\
\hline & Exp. number 4 & $81.43 \%$ & $11.78 \%$ & $3.06 \%$ & $1.95 \%$ & $1.78 \%$ & 1.57 & 2.76 \\
\hline & Exp. number 5 & $57.17 \%$ & $23.94 \%$ & $10.45 \%$ & $4.53 \%$ & $3.91 \%$ & 0.92 & 2.12 \\
\hline \multirow{3}{*}{ Oil-wet } & Exp. number 8 & $96.66 \%$ & $1.08 \%$ & $0.85 \%$ & $0.75 \%$ & $0.66 \%$ & 18.9 & 25.9 \\
\hline & Exp. number 9 & $80.73 \%$ & $14.45 \%$ & $2.67 \%$ & $1.24 \%$ & $0.91 \%$ & 3.70 & 7.10 \\
\hline & Exp. number 10 & $73.51 \%$ & $16.13 \%$ & $6.15 \%$ & $3.21 \%$ & $1.00 \%$ & 1.02 & 1.79 \\
\hline
\end{tabular}

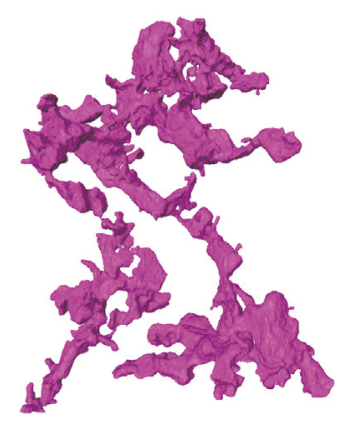

(a)

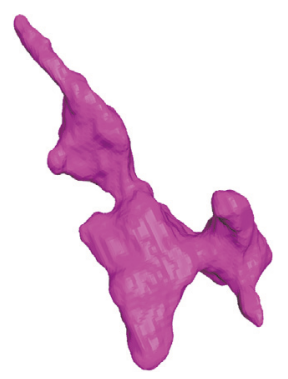

(b)

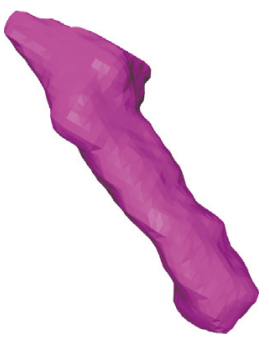

(c)

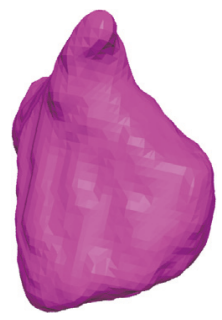

(d)

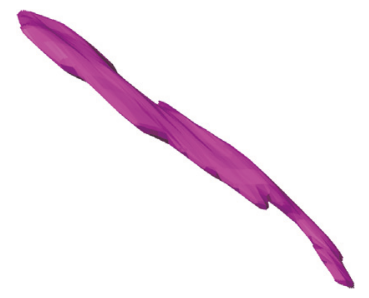

(e)

FIGURE 9: Morphologies and volumes of the five types of oil clusters after 1-PV water drainage in oil-wet plug: (a) clustered (volume $=6.07$ $\left.\times 10^{6} \mu \mathrm{m}^{3}\right)$; (b) multiporous (volume $\left.=3.89 \times 10^{5} \mu \mathrm{m}^{3}\right) ;(\mathrm{c})$ columnar $\left(\right.$ volume $\left.=9.3 \times 10^{4} \mu \mathrm{m}^{3}\right) ;(\mathrm{d})$ droplet $\left(\right.$ volume $\left.=3.08 \times 10^{3} \mu \mathrm{m}^{3}\right) ;(\mathrm{e})$ membranous (volume $=2.17 \times 10^{3} \mu \mathrm{m}^{3}$ ).

3.4. Cluster Morphologies and Classification. It can be seen from the above section that the distribution of oil cluster size shows a big change after water flooding (Figure 6), but the dynamic change rule of various oil clusters, such as the cluster volume, occurrence state, and the number of pores occupied by individual oil cluster, cannot be presented during the water flooding process. The individual remaining oil cluster exists in the pores in different forms, some exist in several connected pores, and others exist in single pore (Figure 8). Meanwhile the oil clusters in various forms have different volume. In order to better describe the different types of remaining oil, the method proposed by Li has been adopted to divide the remaining oil into five categories [36], clustered, multiporous, columnar, droplet, and membranous; see Figure 9. The five categories of oil clusters have different values of volume, surface area, occurrence pore throat ratio, and contact area, which can be quantitatively characterized according to the shape factor, Euler number, and the pore throat contact relationship.

Table 3 shows the variation of the saturation for the five categories of oil clusters during water flooding. It was observed that the volume contribution of the clustered remaining oil is far more than the sum of other four categories of remaining oil at different displacement stage. Only the relative volume of the clustered oil was reduced, and the other four types of remaining oil were increased. This could be in part due to the clustered oil scattered at small volumes, which have a tendency to shift to the other four types of remaining oil during plug-flood experiment (Figure 10). Meanwhile the volume and surface area of largest individual oil cluster were reduced gradually, and the volume of largest individual oil cluster of oil-wet plug was clearly larger than water-wet plug (Table 3). Another discovery was that the largest individual oil clusters were always clustered oil and the smallest oil clusters were droplets or membranous oil.

Figure 11 exhibits the cumulative contribution of trapped oil cluster volume versus cluster volume; the oil clusters were divided into five type groups. To generate this figure, the contribution of all oil clusters with volumes smaller than or equal to each individual oil cluster size to the total oil volume of each type of trapped oil was calculated for water-wet plug and oil-wet plug. After 100 PVs of oil injection, most of the oil phase is continuous, that is, the clustered oil. For primary drainage of oil-wet plug (Figure 11(b)), we can see that some large individual oil clusters contribute a significant amount to the cumulative volume, and the three-dimensional views can be seen in Figure 10(b), which is different from the results observed in water-wet plug. Besides, the size distribution of the clustered oil of oil-wet plug was observed to be larger than that of water-wet plug. This could be in part due to differences in the pore size distribution, pore throat aspect ratio, and pore connectivity. With the increase of water injection volume, (1) some large clustered oil scattered at small volumes, and the slope of the curve increases from the "initial" to the "100-PV" experiment (from right to left); (2) the size distribution of multiporous oil was an increasing trend, and the curve moves from left to right; (3) the columnar oil size was almost constant, and the slope of the curve remains very steep; (4) the range of cluster size distribution of the droplet and membranous oil gradually becomes concentrated 


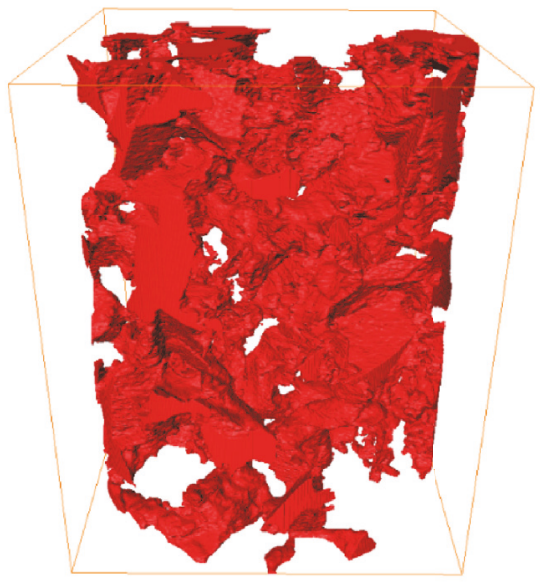

(a)

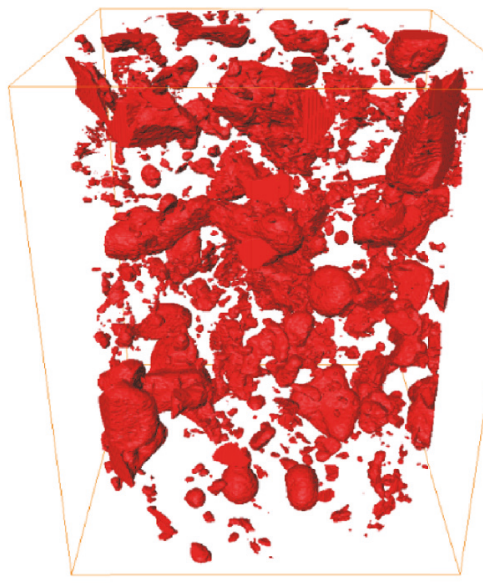

(b)

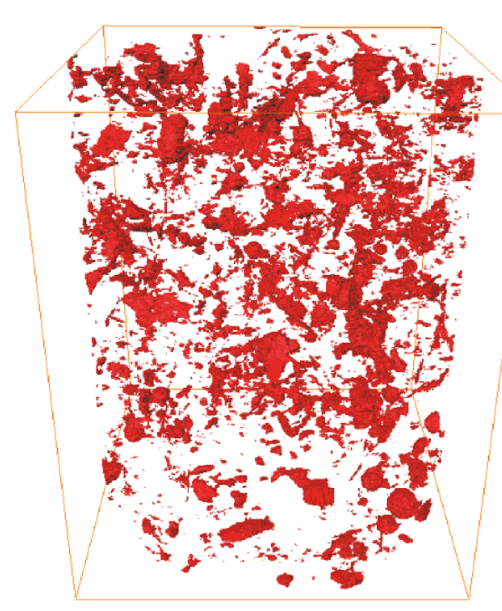

(c)

FIGURE 10: The characteristics of remaining oil during the plug-flood experiment in oil-wet plug. (a) Exp. number 8; (b) Exp. number 9; (c) Exp. number 10 .

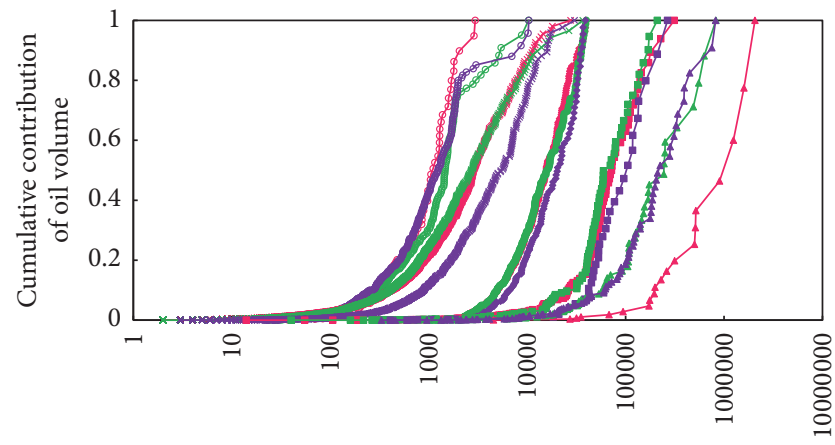

Oil cluster size $\left(\right.$ voxel $\left.^{3}\right)$

(a)

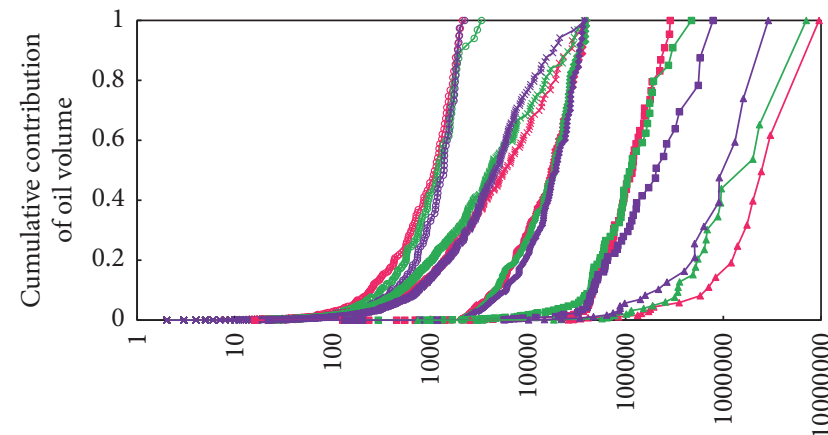

Oil cluster size (voxel $\left.{ }^{3}\right)$

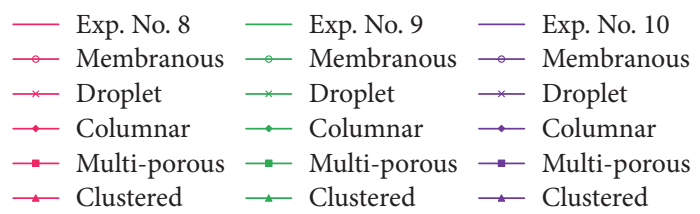

(b)

FIGURE 11: Cumulative contribution of various oil clusters to the overall oil volume during the water flooding experiments: (a) water-wet plug; (b) oil-wet plug.

and the slope of the curve increased slightly. The dynamic change of the cluster size of the droplet and membranous oil is the process in which the pore-scale fluid reaches the low energy stable state. It indicated that it was difficult to improve droplet and membranous oil recovery only by water flooding.

The remaining clustered oil is able to exist in such a large volume of continuous phase, requiring good connectivity of the pores. Besides, the clustered oil generally occupied wellconnected larger pores, so that it cannot be scattered by snapping off. Figure 12 showed the radius distribution of the pores occupied by oil. Large and medium pores accounted for most of the oil volume after fully saturated oil, and the curve showed bimodal distribution (Figure 12(b)). After 1
PV of water drive, the oil in the large pores was preferentially displaced, which dramatically decreased the large pores contribution of oil volume. Therefore, the change of clustered oil cumulative size distribution curve was the most obvious (Figure 11). The remaining oil saturation reduced, but the volume proportion of remaining oil in medium- and small-sized pores increased. After 100-PV water flooding, the trapped oil in the small-sized pores mostly accounted for the oil volume, and the curve peak increased. Compared with oil-wet plug, pores radius of the water-wet plug showed a narrower distribution; the contribution curve of oil volume in target pore was unimodal. During the displacement process, the remaining oil in the pores of various radius was displaced uniformly, so the curve change trend is not obvious 

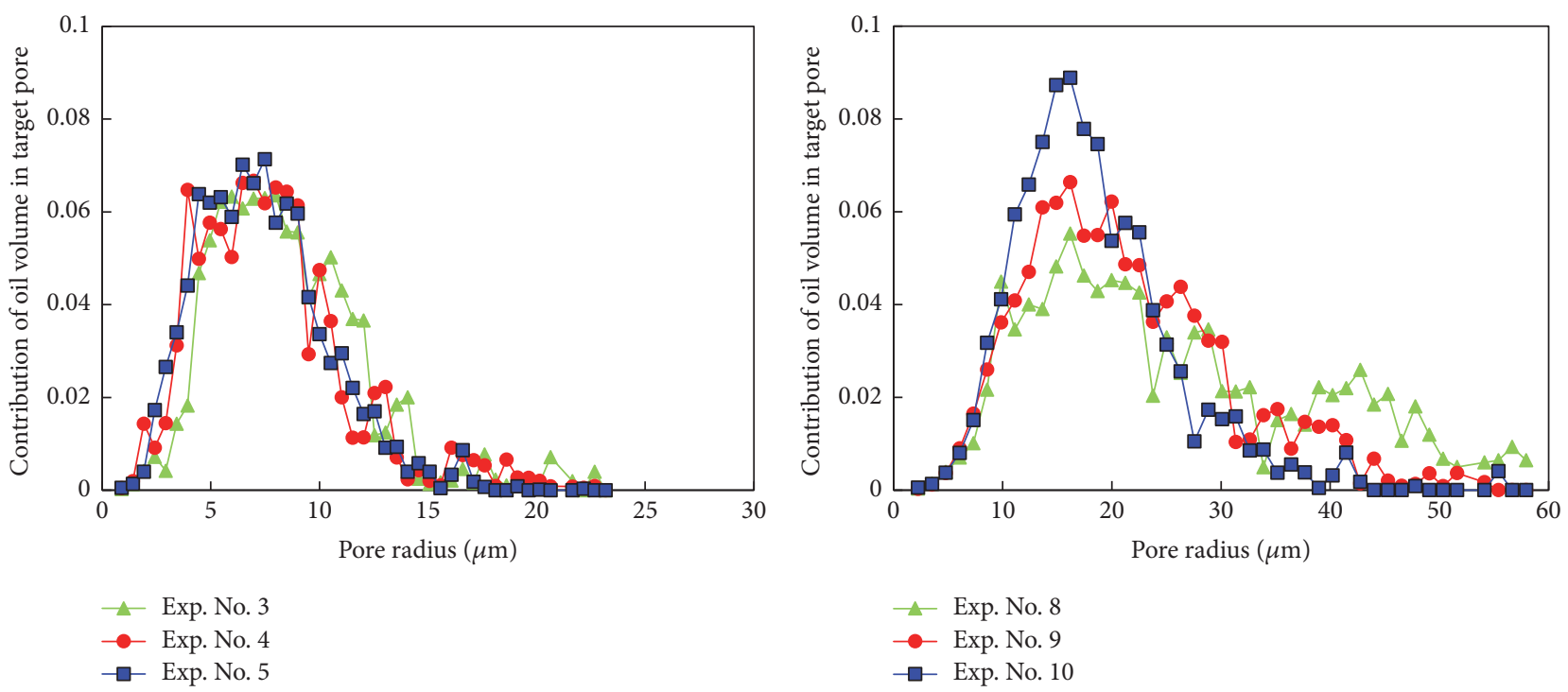

(a)

(b)

FIGURE 12: Contribution of oil volume versus target pore radius during the water flooding experiments: (a) water-wet plug; (b) oil-wet plug.

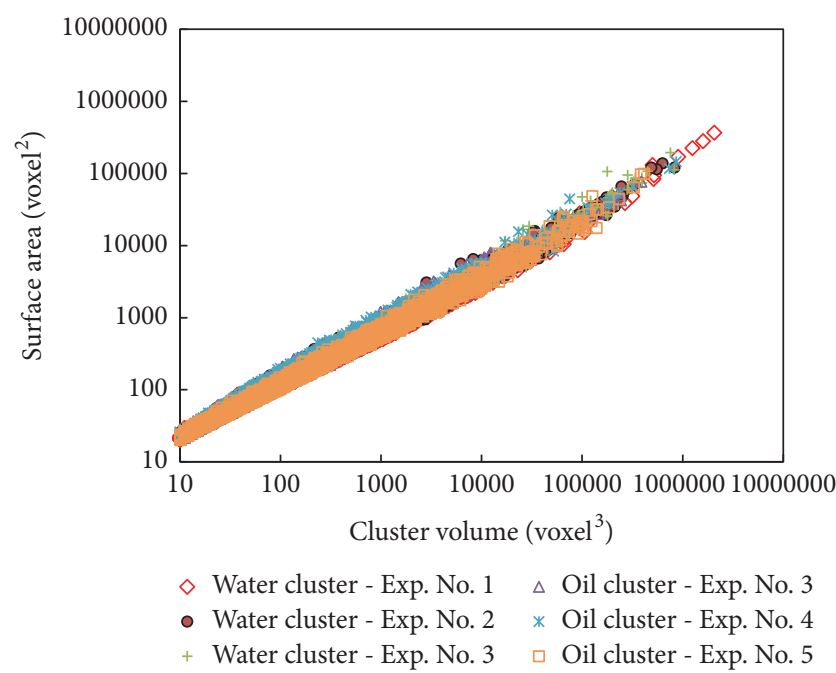

(a)

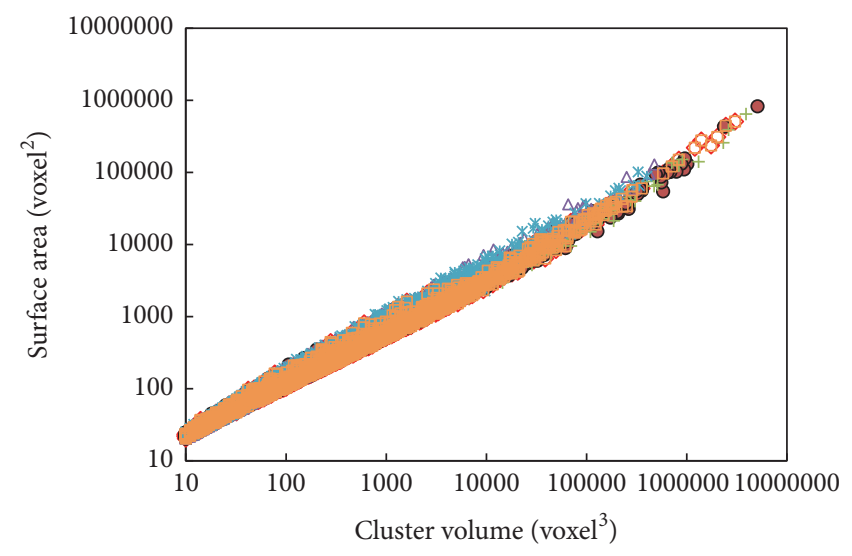

$\diamond$ Water cluster - Exp. No. $6 \quad \Delta$ Oil cluster - Exp. No. 8

- Water cluster - Exp. No. 7 * Oil cluster - Exp. No. 9

+ Water cluster - Exp. No. $8 \quad \square$ Oil cluster - Exp. No. 10

(b)

FIGURE 13: Water and oil cluster surface areas in the entire displacement processes plotted against cluster volumes: (a) water-wet plug; (b) oil-wet plug.

(Figure 12(a)). For this we think, in addition to the effects of pore size and connectivity distributions, the wettability of the plug also has a significant effect. The capillary pressure for the water-wet plug is favorable for oil recovery. But the remaining oil in the small pores of the oil-wet plug is relatively hard to remove, resulting in a gradual increase in the proportion of remaining oil in the small pores during the drainage (Figures $8(d)-8(f))$.

3.5. Cluster Interfacial Areas. The relationships between water and oil cluster volume, $V$, and their surface areas, $A$, in different displacement states are illustrated in Figure 13. Consistent with existing studies, the results followed the power-law correlation given by $A \sim V^{p}[15,35]$. With an increasing injection volume of the displacing phase, the specific surface area of each cluster constantly changed. For the wetting phase, the exponent, $p$, decreased slightly, as presented in Table 2. Conversely, for the nonwetting phase, the $p$ value remained constant, which was consistent with the finding of Iglauer et al. (Iglauer et al., 2015 [16]), as illustrated in Table 2. The nonwetting fluid tended to occupy the pore center, and the specific surface area was relatively stable. In contrast, the wetting phase fluid tended to occupy corners of the pore space, and its specific surface area was significantly influenced by the pore structure. In the water-wet plug, the remaining oil blobs always tend to occupy the center of the 

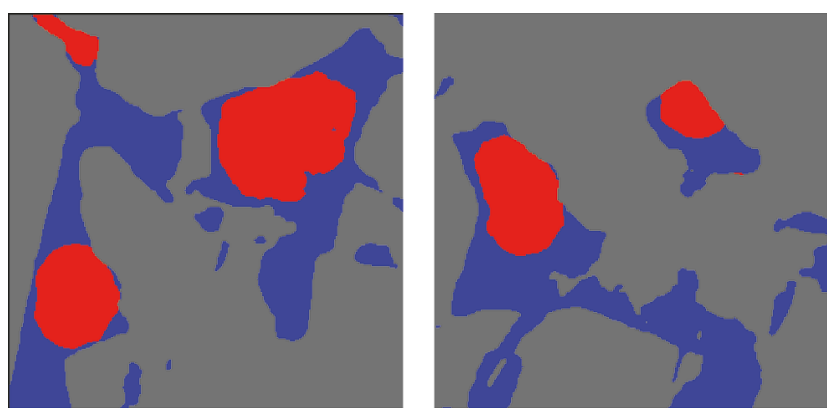

(a)
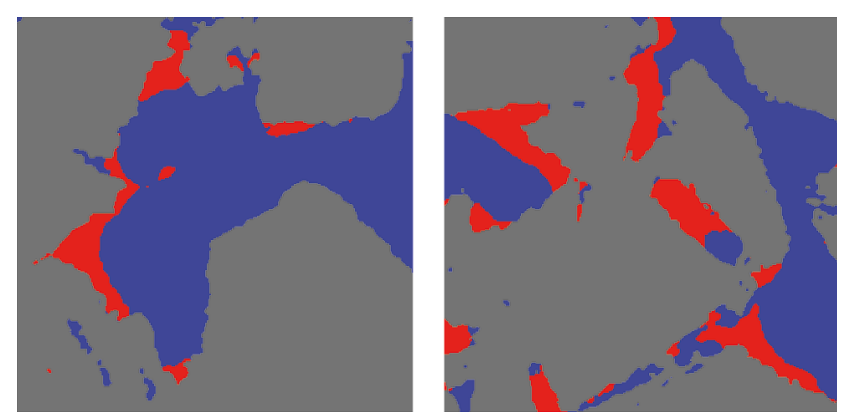

(b)

FIGURE 14: The morphology and distribution of oil-water phase interfaces in water-wet plug (a) and oil-wet plug (b) at the end of 1-PV water flooding.

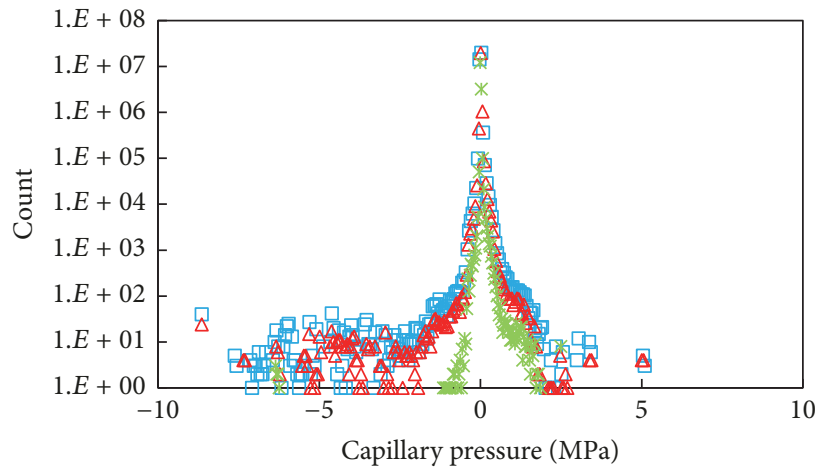

$\square$ Exp. No. 3

$\triangle$ Exp. No. 4

* Exp. No. 5

(a)

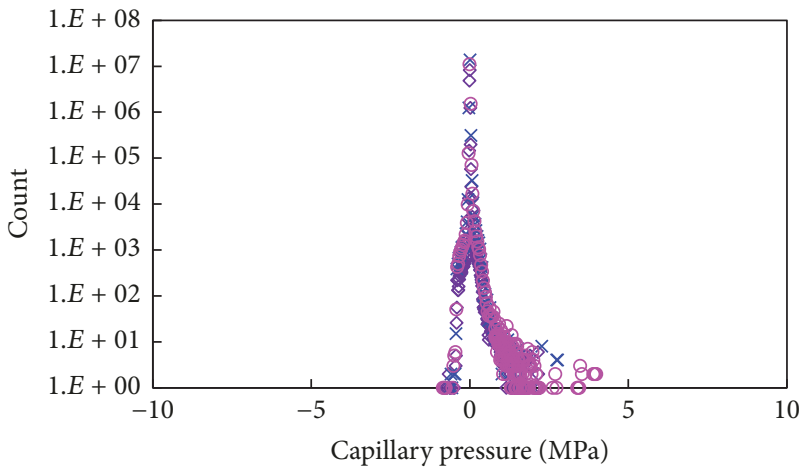

$\diamond$ Exp. No. 8

$\times$ Exp. No. 9

o Exp. No. 10

(b)

FIGURE 15: Capillary pressure distributions of oil in water-wet (a) and oil-wet (b) plug during the plug-flood experiments.

pores in the form of ellipsoids, which have the stable smaller specific surface area, so the $p$ value remained constant. In oil-wet plug, the remaining oil blobs that tend to occupy the pores corner and attach on the walls of the pores have a large surface area. The corner and wall of the pores usually have a very complex structure, which together lead to a larger specific surface area in the range of small oil cluster, and cause a downward trend of the $p$ value. It is clear that the value of $p$ was lower than that predicted by the percolation theory, which implies $p=1$ [37]. Both $\tau$ and $p$ indicated that simple percolation models are unable to accurately predict multiphase fluid transport in porous media, as discussed by other researchers $[20,21,26]$.

3.6. Capillary Pressures Distributions. We used Avizo to calculate the curvature for a discrete triangular surface of segmented image. The capillary pressure, $P_{c}$, for each cluster was then calculated using the Young-Laplace equation, $P_{c}=$ $2 \sigma k$, where $\sigma$ is the interfacial tension and $k$ is the mean curvature, as presented in Figure 15. Similar to previous studies [38], we found that the capillary pressure distribution generally shows a high peak around zero, which is similar to capillary pressure distributions in gas-liquid systems (Iglauer et al., 2015 [26, 39]). Specifically, capillary pressures ranged from $-10 \mathrm{MPa}$ to $+5 \mathrm{MPa}$ of water-wet plugs and $-1 \mathrm{MPa}$ to $+4 \mathrm{MPa}$ of oil-wet plugs. The development of water capillary pressures distributions was not clear during the drainage. When it comes to oil capillary pressures, $P_{c}$ values converged at lower values without a high-value tail in water-wet plugs (after 100 PVs of water imbibition).

In water-wet system, capillary pressure is favorable for oil recovery; oil clusters in corner of pores with high capillary pressures can be preferentially mobilized, and there was almost no corner oil (with higher $P_{c}$ ) in Figure 8(c). In the meanwhile, the disconnected oil blobs with lower curvatures which were generated from oil clusters collected or snapoff became trapped in center of pores space (Figure 14(a)). So the inner diameter of "bell-tower" gradually shrinks, as seen in Figure 15(a). On the other hand, the change of the $P_{c}$ values in oil-wet plugs was not apparent (Figure 15(b)), and the capillary pressure distribution of oil-wet plugs was narrower than of water-wet plug. The reason is that most oil-water phase interfaces were formed in large pores and approximately along the pore wall (with lower $P_{c}$ ) during the water flooding process; the remaining oil in the pores corner (with higher $P_{c}$ ) was difficult to remove (Figure 14(a)). With 
the increase of water injection (Figures $8(\mathrm{e})$ and $8(\mathrm{f})$ ), only the oil layer attached to the wall became thinner and new remaining oil was generated in the pore corner. The shape (curvature) of the oil-water phase interface showed almost no change, so the range of capillary pressure did not change obviously. Furthermore, the X-ray CT scanning resolution and scanning time may have influences on curvature measurement $[38,40]$. Therefore, more accurate experiments and measurement mothed are needed to discuss the interface curve and capillary pressure.

\section{Conclusions}

We investigated the microscopic characteristics of trapped clusters for water-wet and oil-wet sandstones in different flow stages using X-ray CT scanning. We observed a significantly lower residual oil saturation in the oil-wet plug $(19.8 \%)$ than in an analogue water-wet sandstone (25.2\%). We found an approximate power-law distribution of the size and specific surface area of the water and oil cluster, and the changes of the exponent are different in the two plugs. The trapped oil tends to occupy the center of pores in water-wet plug while it tends to occupy the pore corner and attach to the pore wall in oil-wet plug. All of the changes and differences illustrated that the wettability has significant influence on fluid distribution in sandstone. We divided the remaining oil into five categories, clustered, multiporous, columnar, droplet, and membranous, according to the shape factor, Euler number, and the pore throat contact relationship. The clustered oil would scatter at small volumes to shift to the other four types of remaining oil during water flooding process. On the other hand, the different wettability of the two porous media affects the curvature of the water-oil interface and thus the capillary pressures of the two porous media. In the water-wet system, the oil $P_{c}$ values gradually converged at lower values without a high-value tail in water-wet plugs. But the change of the $P_{c}$ values in oil-wet plugs was not obvious in the plug-flood experiment. All the results demonstrated that wettability, pore size distribution, and pore connectivity have a strong impact on fluid saturations, cluster morphologies, and potentially cluster size distributions.

\section{Conflicts of Interest}

The authors declare that they have no conflicts of interest.

\section{Acknowledgments}

This research was supported by the National Natural Science Foundation (Grant 51674271) and National Science and Technology Major Project (2017ZX05009-005). The authors also wish to appreciate the Key Laboratory of Petroleum Resources and Prospecting and iRock Technologies Co., Ltd.

\section{References}

[1] F. Kalaydjian, "A macroscopic description of multiphase flow in porous media involving spacetime evolution of fluid/fluid interface," Transport in Porous Media, vol. 2, no. 6, pp. 537-552, 1987.
[2] S. M. Hassanizadeh and W. G. Gray, "Thermodynamic basis of capillary pressure in porous media," Water Resources Research, vol. 29, no. 10, pp. 3389-3405, 1993.

[3] D. Chen, L. J. Pyrak-Nolte, J. Griffin, and N. J. Giordano, "Measurement of interfacial area per volume for drainage and imbibition," Water Resources Research, vol. 43, no. 12, Article ID W12504, 2007.

[4] Y. Zhou, J. O. Helland, and D. G. Hatzignatiou, "Pore-scale modeling of waterflooding in mixed-wet-rock images: Effects of initial saturation and wettability," SPE Journal, vol. 19, no. 1, pp. 88-100, 2014.

[5] M. Blunt and P. King, "Relative permeabilities from two- and three-dimensional pore-scale network modelling," Transport in Porous Media, vol. 6, no. 4, pp. 407-433, 1991.

[6] P. H. Valvatne and M. J. Blunt, "Predictive pore-scale modeling of two-phase flow in mixed wet media," Water Resources Research, vol. 40, no. 7, Article ID W07406, 2004.

[7] G. Løvoll, Y. Méheust, K. J. Måløy, E. Aker, and J. Schmittbuhl, "Competition of gravity, capillary and viscous forces during drainage in a two-dimensional porous medium, a pore scale study," Energy, vol. 30, no. 6, pp. 861-872, 2005.

[8] R. S. Seright, M. Prodanovic, and W. B. Lindquist, "X-ray computed microtomography studies of fluid partitioning in drainage and imbibition before and after gel placement: Disproportionate permeability reduction," SPE Journal, vol. 11, no. 2, pp. 159-170, 2006.

[9] O. A. Olafuyi, A. P. Sheppard, C. H. Arns et al., "Experimental investigation of drainage capillary pressure computed from digitized tomographic images," in Proceedings of the SPE/DOE Symposium on Improved Oil Recovery, Tulsa, Oklahoma, USA, 2006.

[10] R. Dann, M. Turner, M. Close, and M. Knackstedt, "Multi-scale characterisation of coastal sand aquifer media for contaminant transport using X-ray computed tomography," Environmental Earth Sciences, vol. 63, no. 5, pp. 1125-1137, 2011.

[11] M. Kumar, T. J. Senden, A. P. Sheppard, C. H. Arns, and M. A. Knackstedt, "Probing the archie's exponent under variable saturation conditions," Petrophysics, vol. 52, no. 2, pp. 124-134, 2011.

[12] C. J. Landry, Z. T. Karpyn, and M. Piri, "Pore-scale analysis of trapped immiscible fluid structures and fluid interfacial areas in oil-wet and water-wet bead packs," Geofluids, vol. 11, no. 2, pp. 209-227, 2011.

[13] J. G. Celauro, V. A. Torrealba, Z. T. Karpyn, K. A. Klise, and S. A. Mckenna, "Pore-scale multiphase flow experiments in bead packs of variable wettability," Geofluids, vol. 14, no. 1, pp. 95-105, 2014.

[14] M. Kumar, T. Senden, M. A. Knackstedt et al., "Imaging of pore scale distribution of fluids and wettabilityl," Petrophysics, vol. 50, no. 4, pp. 311-321, 2009.

[15] Z. T. Karpyn, M. Piri, and G. Singh, "Experimental investigation of trapped oil clusters in a water-wet bead pack using X-ray microtomography," Water Resources Research, vol. 46, no. 4, Article ID W04510, 2010.

[16] S. Iglauer, M. A. Fernø, P. Shearing, and M. J. Blunt, "Comparison of residual oil cluster size distribution, morphology and saturation in oil-wet and water-wet sandstone," Journal of Colloid and Interface Science, vol. 375, no. 1, pp. 187-192, 2012.

[17] K. Singh, B. Bijeljic, and M. J. Blunt, "Imaging of oil layers, curvature and contact angle in a mixed-wet and a water-wet carbonate rock," Water Resources Research, vol. 52, no. 3, pp. 1716-1728, 2016. 
[18] S. Iglauer, A. Paluszny, C. H. Pentland, and M. J. Blunt, "Residual $\mathrm{CO}_{2}$ imaged with X-ray micro-tomography," Geophysical Research Letters, vol. 38, no. 21, Article ID L21403, 2011.

[19] S. Iglauer, A. Paluszny, and M. J. Blunt, "Simultaneous oil recovery and residual gas storage: A pore-level analysis using in situ X-ray micro-tomography," Fuel, vol. 103, pp. 905-914, 2013.

[20] S. Iglauer, T. Rahman, M. Sarmadivaleh, A. Al-Hinai, M. A. Fernø, and M. Lebedev, "Influence of wettability on residual gas trapping and enhanced oil recovery in three-phase flow: A pore-scale analysis by use of microcomputed tomography," SPE Journal, vol. 21, no. 6, pp. 1916-1929, 2016.

[21] S. Iglauer and W. Wülling, "The scaling exponent of residual nonwetting phase cluster size distributions in porous media," Geophysical Research Letters, vol. 43, no. 21, pp. 11-260, 2016.

[22] M. Andrew, B. Bijeljic, and M. J. Blunt, "Pore-scale imaging of geological carbon dioxide storage under in situ conditions," Geophysical Research Letters, vol. 40, no. 15, pp. 3915-3918, 2013.

[23] M. Andrew, B. Bijeljic, and M. J. Blunt, "Pore-scale contact angle measurements at reservoir conditions using X-ray microtomography," Advances in Water Resources, vol. 68, pp. 24-31, 2014.

[24] A. Georgiadis, S. Berg, A. Makurat, G. Maitland, and H. Ott, "Pore-scale micro-computed-tomography imaging: Nonwetting-phase cluster-size distribution during drainage and imbibition," Physical Review E: Statistical, Nonlinear, and Soft Matter Physics, vol. 88, no. 3, Article ID 033002, 2013.

[25] H. Geistlinger and S. Mohammadian, "Capillary trapping mechanism in strongly water wet systems: Comparison between experiment and percolation theory," Advances in Water Resources, vol. 79, pp. 35-50, 2015.

[26] T. Rahman, M. Lebedev, A. Barifcani, and S. Iglauer, "Residual trapping of supercritical $\mathrm{CO}_{2}$ in oil-wet sandstone," Journal of Colloid and Interface Science, vol. 469, pp. 63-68, 2016.

[27] K. C. Carroll, K. McDonald, J. Marble, A. E. Russo, and M. L. Brusseau, "The impact of transitions between two-fluid and three-fluid phases on fluid configuration and fluid-fluid interfacial area in porous media," Water Resources Research, vol. 51, no. 9, pp. 7189-7201, 2015.

[28] E. Amott, "Observations relating to the wettability of porous media," Transaction of American Institute of Mining, Metallurgical, and Petroleum Engineers (AIME), vol. 216, pp. 156-162, 1959.

[29] A. Buades, B. Coll, and J. M. Morel, "A non-local algorithm for image denoising," in Proceedings of the IEEE Computer Society Conference on Computer Vision \& Pattern Recognition. IEEE Computer Society, vol. 4, pp. 60-65, San Diego, Calif, USA, June 2005.

[30] H.-J. Vogel and K. Roth, "Quantitative morphology and network representation of soil pore structure," Advances in Water Resources, vol. 24, no. 3-4, pp. 233-242, 2001.

[31] C. H. Pentland, R. El-Maghraby, S. Iglauer, and M. J. Blunt, "Measurements of the capillary trapping of super-critical carbon dioxide in Berea sandstone," Geophysical Research Letters, vol. 38, no. 6, Article ID L06401, 2011.

[32] M. M. Dias and D. Wilkinson, "Percolation with trapping," Journal of Physics A: General Physics, vol. 19, no. 15, article 034, pp. 3131-3146, 1986.

[33] M. Blunt, M. J. King, and H. Scher, "Simulation and theory of two-phase flow in porous media," Physical Review A: Atomic, Molecular and Optical Physics, vol. 46, no. 12, pp. 7680-7699, 1992.

[34] C. D. Lorenz and R. M. Ziff, "Precise determination of the bond percolation thresholds and finite-size scaling corrections for the sc, fcc, and bcc lattices," Physical Review E: Statistical Physics, Plasmas, Fluids, and Related Interdisciplinary Topics, vol. 57, no. 1, pp. 230-236, 1998.

[35] C. H. Pentland, S. Iglauer, O. Gharbi, K. Okada, and T. Suekane, "The influence of pore space geometry on the entrapment of carbon dioxide by capillary forces," in Proceedings of the SPE Asia Pacific Oil and Gas Conference and Exhibition, Perth, Australia, 2012.

[36] J. Li, H. Jiang, C. Wang et al., "Pore-scale investigation of microscopic remaining oil variation characteristics in water-wet sandstone using CT scanning," Journal of Natural Gas Science \& Engineering, vol. 48, pp. 36-45, 2017.

[37] D. Stauffer, "Scaling theory of percolation clusters," Physics Reports, vol. 54, no. 1, pp. 1-74, 1979.

[38] R. T. Armstrong, M. L. Porter, and D. Wildenschild, "Linking pore-scale interfacial curvature to column-scale capillary pressure," Advances in Water Resources, vol. 46, pp. 55-62, 2012.

[39] M. Andrew, B. Bijeljic, and M. J. Blunt, "Pore-scale imaging of trapped supercritical carbon dioxide in sandstones and carbonates," International Journal of Greenhouse Gas Control, vol. 22, pp. 1-14, 2014.

[40] M. Khishvand, M. Akbarabadi, and M. Piri, "Micro-scale experimental investigation of the effect of flow rate on trapping in sandstone and carbonate rock samples," Advances in Water Resources, vol. 94, pp. 379-399, 2016. 

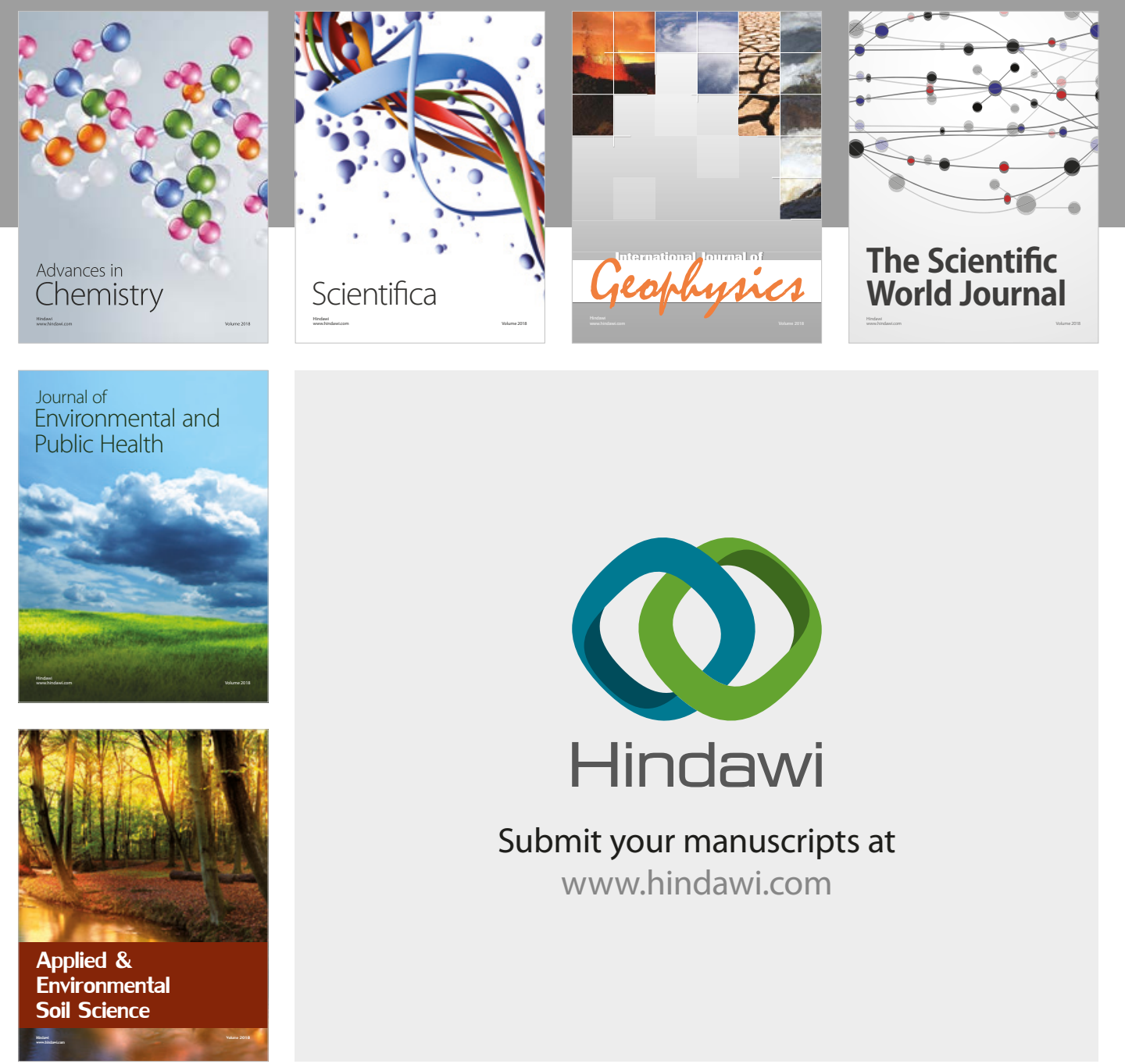

The Scientific

\section{World Journal}
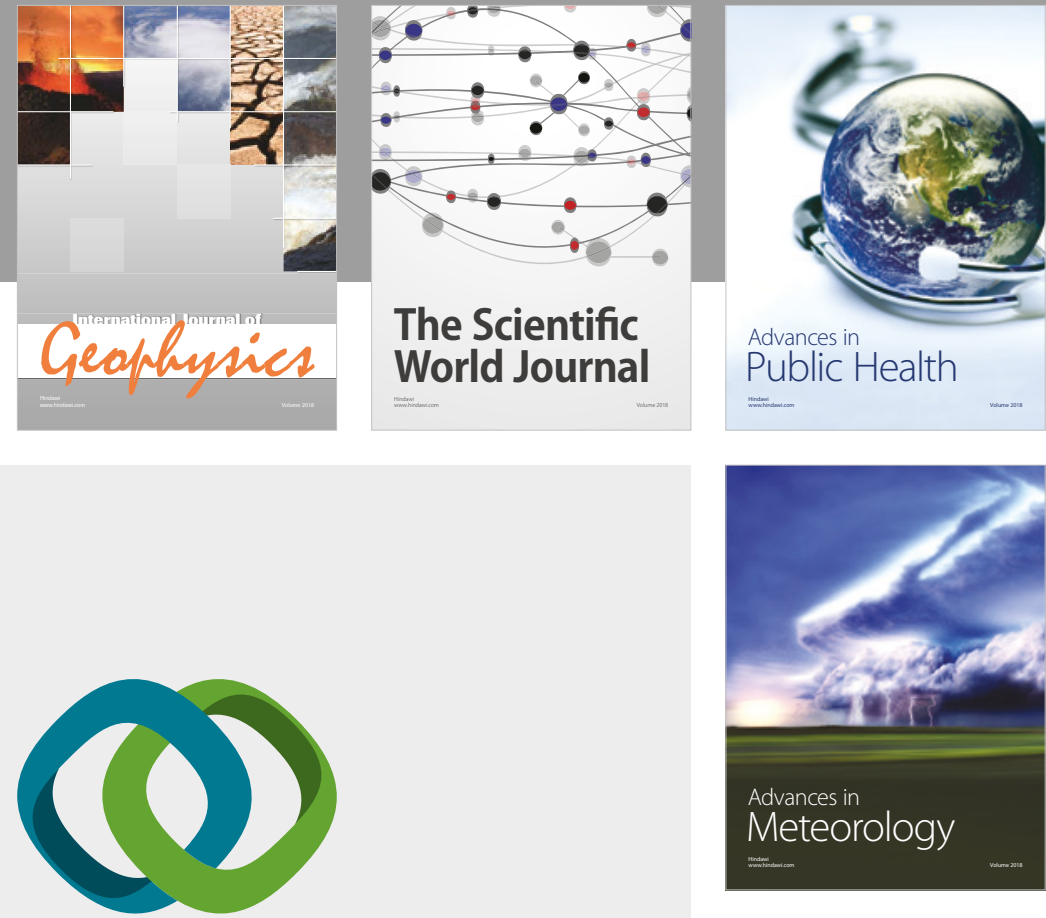

Advan

Public Health

\section{Hindawi}

Submit your manuscripts at

www.hindawi.com
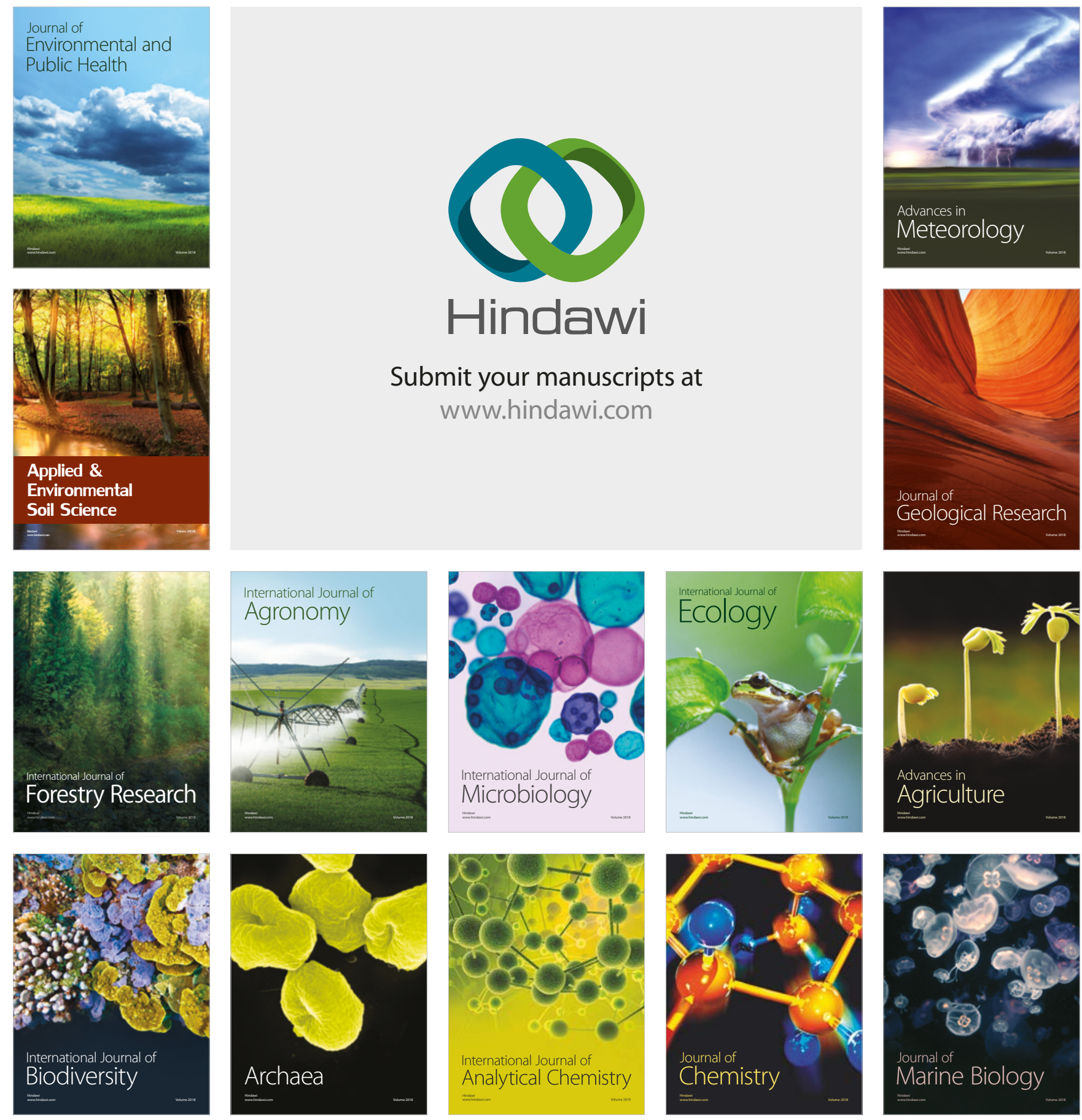